\title{
THE DISSOCIATIVE IONIZATION OF CARBON MONOXIDE
}

\author{
R. LOCHT \\ Institut de Chimie, Département de Chimie Générale et de Chimie Physique, Sart-Tilman Par, B-4000 Liège 1, \\ Belgium
}

\begin{abstract}
The dissociative ionization of $\mathrm{CO}$ by low energy electron impact into $\mathrm{C}^{+}+\mathrm{O}$ (or $\mathrm{O}^{-}$) and $\mathrm{O}^{+}+\mathrm{C}$ (or $\mathrm{C}^{-}$) is investigated using ion energy and mass analysis. The kinetic energy distributions are studied as a function of the impinging electron energy. The threshold energies of $\mathrm{C}^{+}$and $\mathrm{O}^{+}$are measured as a function of the released kinetic energy. The formation of the products in their ground level and with a small amount of kinetic energy mainly occurs through predissociation. The $\mathrm{CO}^{+}$electronic states involved in these processes are tentatively identified. New evidences have been found for the importance of dissociative ionization via autoionization.
\end{abstract}

\section{Introduction}

Up to now the careful analysis and the interpretation of the translational energy spectra of ionized fragments produced by dissociative ionization by means of low energy electron (or photon) impact has proved to be a powerful technique in order to obtain valuable information about repulsive and predissociated states of molecular ions. The dissociative ionization of diatomic molecules has been the subject of an increasing number of papers during the last few years. However most of the efforts have been focussed on the most important diatomic and triatom-ic molecules in aeronomy and astrophysics.

The main interest of a careful investigation of the dissociative ionization of a molecule like $\mathrm{CO}$ is twofold: (i) carbon monoxide is isoelectronic with the frequently investigated $\mathrm{N}_{2}$ molecule and (ii) the data available from theoretical as well as experimental work devoted to this species are rather scarce.

Hitherto only the $\mathrm{X}^{2} \Sigma^{+}$, the $\mathrm{A}^{2} \Pi_{\mathrm{i}}$ and the $\mathrm{B}^{2} \Sigma^{+}$states of $\mathrm{CO}^{+}$are spectroscopically well known [1]. It is only recently that experimental data became available above the $21.21 \mathrm{eV}$ limit obtained with the $\mathrm{He}(\mathrm{I})$ resonance line at $584 \AA$. The ${ }^{2} \Delta$ molecular ion state, excited by energy transfer with $\mathrm{Ne}$ in a discharge, has been observed at $21.76 \mathrm{eV}$ in emission toward the $\mathrm{A}^{2} \Pi_{\mathrm{i}}$ state by Marchand et al. [2]. Rydberg series converging to the higher lying $\mathrm{C}^{2} \Sigma^{+}, \mathrm{E}^{2} \Sigma^{+}, \mathrm{F}^{2} \Sigma^{+}$and $\mathrm{D}^{2} \Pi$ states of $\mathrm{CO}^{+}$were observed in absorption by means of electron synchrotron radiation [3]. These states, identified by photo-electron spectroscopy in the energy range of $21 \mathrm{eV}$ to $29 \mathrm{eV}$, were excited by the $304 \AA \mathrm{He}(\mathrm{II})$ resonance line [3,4]. Rydberg series as well as highly excited states were detected in the electroionization efficiency curve of $\mathrm{CO}^{+}$by Carbonneau and Marmet [5].

Even fewer are the theoretical calculations on the excited states of $\mathrm{CO}^{+}$in the energy range where dissociative ionization occurs. Lefebvre-Brion and Moser [6] and Guerin [7] calculated the energy of Rydberg states and potential energy curves of the first electronic states of $\mathrm{CO}^{+}$. No data at all exist about $\mathrm{CO}^{+}$electronic states which are repulsive within the Franck-Condon region.

Most of the data about the dissociative ionization of carbon monoxide are available from electron impact work. Beneath dissociation limits defined by appearance potential measurements on the fragments derived from ionization efficiency curves [8], only a few dissociative ionization studies have been made with ion energy analysis, necessary for unambiguous assignment. Hagstrum [9] performed ion energy analysis using the retarding potential technique, and appearance potential measurements on both $\mathrm{C}^{+}$and $\mathrm{O}^{+}$fragments. Stanton and Monahan [10] published the ion energy spectra of $\mathrm{C}^{+}$and $\mathrm{O}^{+}$at a fixed electron energy. In a double focussing mass spectrometer, Wankenne and Momigny [11] observed metastable transitions corresponding to the formation of $\mathrm{C}^{+}$and $\mathrm{O}^{+}$in the first field free region. Kinetic energy and appearance potentials of these species have been measured. Köllmann [12] was the first to investigate the ion energy distribution of $\mathrm{C}^{+}$and $\mathrm{O}^{+}$from $\mathrm{CO}$ as a function of the angle $\theta$ between the electron and ion beams. In principle this kind of experiment allows one to ascribe symmetries to the dissociative molecular ion states based upon Dunn's selection rules [13]. More recently, Smyth et al. [14] studied the dissociative excitation of CO by translational spectroscopy of long-lived high-Rydberg $\mathrm{C}$ and $\mathrm{O}$ atoms. Their results were interpreted in terms of the corresponding dissociative ionization process. Excitation thresholds were measured as a function of the kinetic energy carried away by the fragments. 
After a preliminary paper [15] we shall report the complete results obtained for both $\mathrm{C}^{+}$and $\mathrm{O}^{+}$ions formed by dissociative ionization induced by low energy electron impact on $\mathrm{CO}$.

\section{Experimental}

\subsection{Apparatus and operating conditions}

The apparatus as well as the experimental conditions have been described in detail elsewhere [16]. Briefly, the experimental set-up consists of four basic units: the ion source, the ion kinetic energy analyzer, the mass spectrometer and the detection system. The ions, formed in an ATLAS AN-4 Nier-type ion source, are focussed at the source exit slit and pass through a retarding region defined by two grids suitably spaced in order to obtain optimum resolution. After being kinetic energy analyzed, the ion beam is accelerated at the entrance hole of a quadrupole mass spectrometer. The ion current corresponding to the desired mass-to-charge ratio $\mathrm{m} / \mathrm{e}$ is collected on a $\mathrm{Cu}-\mathrm{Be}$ electron multiplier. The ion current is continuously scanned as a function of either the electron energy at fixed retarding potential or the retarding potential at fixed electron energy. Both signals, electronically differentiated, are stored in a multichannel analyzer and plotted on an $X$ - $Y$ recorder.

Unless otherwise stated, the operating conditions maintained during this work are strictly identical to those described in the previous studies of the dissociative ionization of $\mathrm{O}_{2}$ [16] and $\mathrm{N}_{2}$ [17]. The carbon monoxide gas, purchased from Air Liquide, is of $99.997 \%$ purity. In the vacuum chamber a pressure of $4 \times 10^{-7}$ torr is kept constant during operation. The electron trap current is stabilized at $1 \mu \mathrm{A}$. The ion accelerating voltage is set at $2.5 \mathrm{~V}$ in which conditions the fwhm of the first derivative of the retarding curve of $\mathrm{CO}^{+}$is $70 \mathrm{meV}$.

\subsection{Calibration and data treatment}

\subsubsection{Kinetic energy scale calibration}

The origin of the kinetic energy scale is taken at the maximum of the first differentiated retarding curve of the $\mathrm{CO}^{+}$molecular ion. When ionization efficiency curves are recorded at fixed retarding potential values, the latter are measured with respect to the same reference. The drift of the maximum of the kinetic energy distribution of $\mathrm{CO}^{+}$is less than $10 \mathrm{mV}$ over a week.

\subsubsection{Electron energy scale calibration}

To calibrate the electron energy scale for the appearance potential measurements of $\mathrm{C}^{+}$, the first ionization potential of $\mathrm{CO}^{+}\left(\mathrm{X}^{2} \Sigma^{+}\right)$at $14.013 \mathrm{eV}$, as determined by spectroscopy from limits of Rydberg series [1], is chosen as a reference. The ionization efficiency curve of $\mathrm{CO}^{+}$has been recorded twice a day to take into account all possible drifts due to contact potentials. For the measurements of appearance energy of $\mathrm{O}^{+}$the first threshold of $\mathrm{C}^{+}$, calculated to be $22.369 \mathrm{eV}$, is used as a reference and has been recorded twice a day. The linearity of the electron energy scale has periodically been checked with respect to the first ionization potential of $\mathrm{CO}^{+}$at $14.013 \mathrm{eV}$.

\subsubsection{Data handling and significant figures}

The kinetic energy distribution spectra have been recorded as a function of the electron energy. Fifty measurements have been performed between the threshold of $\mathrm{C}^{+}$and $40 \mathrm{eV}$. Near threshold the storage time is 48 to $72 \mathrm{~h}$. The position of the maxima is the arithmetic mean of the measured data, and the quoted error represents the standard deviation $\sigma$. Being less than $0.1 \sigma$ the calibration error has been neglected. For the measurements (at least 10) performed in the case of $\mathrm{C}^{+}$as well as of $\mathrm{O}^{+}$at higher electron energies, the error mentioned above represents the average deviation from the arithmetic mean.

As far as ionization efficiency curves are concerned, averaged during $8 \mathrm{~h}$ at least, the threshold is measured at the intercept of the linear extrapolation of the highest slope of the one time differentiated ionization efficiency curve and the electron energy axis $[16,18]$. All threshold energies have been measured independently five times. The scattering of the data points for each measurement will be given by the average deviation $\delta$, the magnitude of which is given by the error bars in figs. 6 and 8. The calibration error is found to be negligible with respect to $\delta$. 
Fig. 1. First derivative of the retarding potential curve of $\mathrm{C}^{+} / \mathrm{CO}$ recorded for $100 \mathrm{eV}$ electrons.

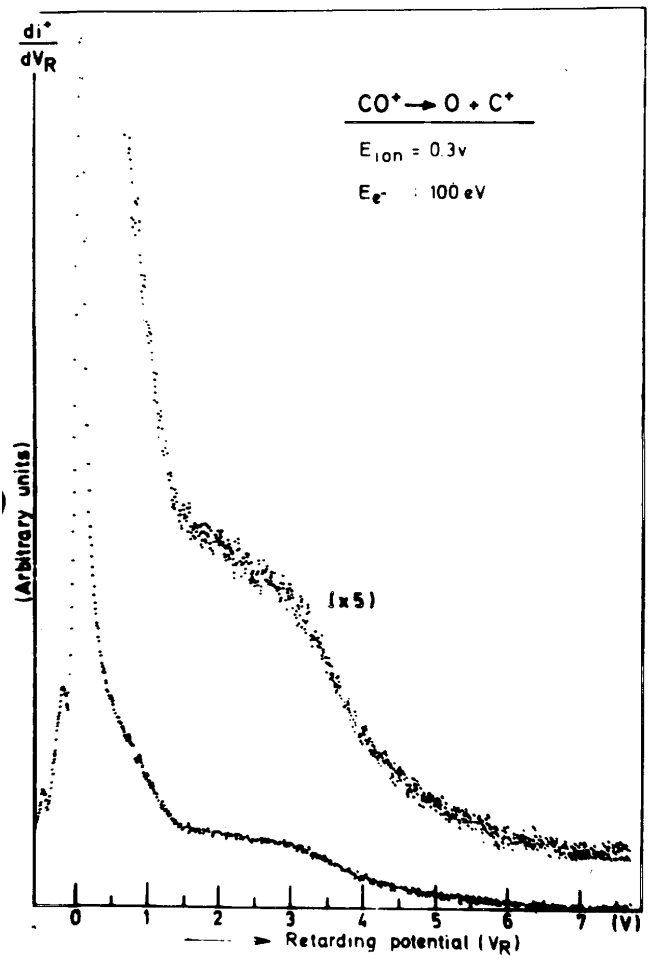

Fig. 2. First derivative of the retarding potential curves of $\mathrm{C}^{+} / \mathrm{CO}$ recorded near the appearance threshold of (1) $\mathrm{CO}^{+} \rightarrow \mathrm{C}^{+}+\mathrm{O}$ and (2) $\mathrm{CO} \rightarrow \mathrm{C}^{+}+\mathrm{O}^{-}$.

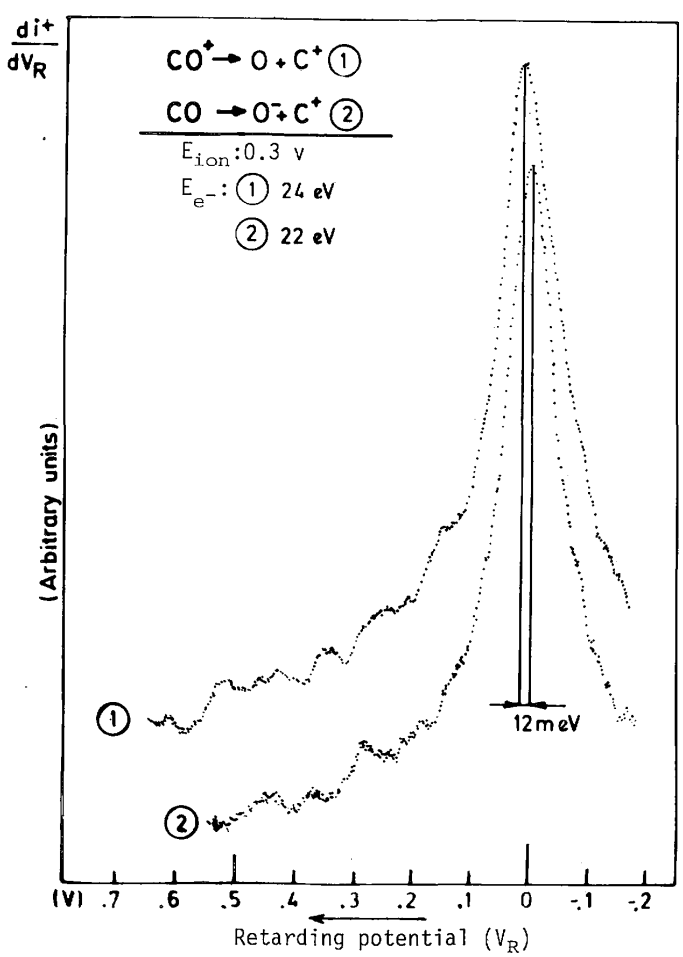




\section{Results}

\subsection{Kinetic energy measurements}

\subsubsection{Dissociation channel $\mathrm{CO} \stackrel{e^{-}}{\longrightarrow} \mathrm{C}^{+}+\mathrm{O}^{-}$and $\mathrm{C}^{+}+\mathrm{O}$}

Fig. 1 shows a typical translational energy distribution of $\mathrm{C}^{+}$produced by $100 \mathrm{eV}$ electrons on $\mathrm{CO}$. This distribution exhibits a thermal or nearly thermal peak, a shoulder at around $0.3 \mathrm{eV}$ and a broad structure around $2.5 \mathrm{eV}$. Köllmann [12] mentions a group of ions peaking at $0.5 \mathrm{eV}$ and a broad distribution having its maximum at about $3.0 \mathrm{eV}$. Between the latter and the present work an unexplained large discrepancy is observed for the relative intensity characterizing each structure. Smyth et al. [14] observed a peak at $0.5 \mathrm{eV}$ and a shoulder around $2.5 \mathrm{eV}$ in the high-Rydberg atoms translational energy spectrum. The careful calibration of the kinetic energy scale with respect to the peak maximum of the $\mathrm{CO}^{+}$distribution allowed us to observe an energy shift of the thermal peak. At $22 \mathrm{eV}$ electron energy the $\mathrm{C}^{+}$thermal peak is observed at $(0 \pm 3) \mathrm{meV}$. In the range of $24-40 \mathrm{eV}$ this peak shifts to $(12 \pm 4) \mathrm{meV}$ (see fig. 2). At 60 and $100 \mathrm{eV}$ electron energy, the lowest energy peak maximum is measured at $(45 \pm 10) \mathrm{meV}$ and at $(70 \pm 15) \mathrm{meV}$, respectively (see fig. 2 in ref. [15] ).

At electron energies near threshold, i.e. in the range of $21-30 \mathrm{eV}$, the $\mathrm{C}^{+}$ion energy spectrum shows a fine structure between $0.0-0.7 \mathrm{eV}$ translational energy (fig. 2). In table 1 are listed the position of the maxima in terms of the total energy, i.e. 28/16 times the measured values, which are directly comparable to spectroscopic data.

\subsubsection{Dissociation channel $\mathrm{CO} \stackrel{e_{-}^{-}}{\longrightarrow} \mathrm{O}^{+}+\mathrm{C}^{+}$and $\mathrm{O}^{+}+\mathrm{C}$}

The kinetic energy distribution of the $\mathrm{O}^{+}$ions produced by dissociative ionization by electron impact on $\mathrm{CO}$ only shows a narrow and nearly thermal peak followed by a broad bell-shaped curve. Typical distributions are reproduced in fig. 3 as observed at different electron energies. The nearly thermal peak is characterized by a maximum measured at $(17 \pm 3) \mathrm{meV}$ (see fig. 4) for $25 \mathrm{eV}$ electrons. The maximum of the high energy peak shifts from $0.8 \mathrm{eV}$ at $30 \mathrm{eV}$ electron energy, up to $2.0 \mathrm{eV}$ at $100 \mathrm{eV}$. The fwhm increases with the impinging electron energy. These observations are in good agreement with Köllmann's experimental results [12]. The existence of a thermal peak near $0 \mathrm{eV}$ kinetic energy has been confirmed by the most recent experiments of this author [12] as well as by appearance potential measurements (see section 4.2). No particular feature has been observed at low ion energies for electron energies near the appearance threshold of $\mathrm{O}^{+}$. However, between 30 and $40 \mathrm{eV}$ electron energy, the sudden change in shape of the high energy peak as well as its sudden and important shift of $0.6 \mathrm{eV}$ to lower ion energies for decreasing electron energies are noteworthy. In the range of $40-100 \mathrm{eV}$ electron energy a shift of only $0.5 \mathrm{eV}$ is observed.

Table 1. Position (in meV) of the submaxima observed in the first derivative of the ion retarding curve of $C^{+}$ from $C O$. The values obtained from the absorption spectrum and the photoelectron spectra $[3,4]$ are calculated with respect to the dissociation limits $\mathrm{D}\left(\mathrm{C}^{+}-\mathrm{O}^{-}\right)=20.904 \mathrm{eV}$ and $\mathrm{D}\left(\mathrm{C}^{+}-\mathrm{O}\right)=22.369 \mathrm{eV}$. The energy conversion factor used is $1 \mathrm{eV}=8065.73 \mathrm{~cm}^{-1}$. The quoted error is the standard deviation $\sigma$

\begin{tabular}{|c|c|c|c|c|}
\hline \multicolumn{2}{|c|}{ (a) Electron energy $21.23 \mathrm{eV}$} & \multicolumn{3}{|c|}{ (b) Electron energy $24-30 \mathrm{eV}$} \\
\hline \multirow[t]{2}{*}{ this work ${ }^{a}$ ) } & \multirow{2}{*}{$\begin{array}{c}\text { absorption } \\
\text { spectrum [3] }\end{array}$} & \multirow[t]{2}{*}{ this work ${ }^{a}$ ) } & \multicolumn{2}{|c|}{ photoelectron spectrum } \\
\hline & & & ref. [3] & ref. [4] \\
\hline $0 \pm 5$ & $-34 \pm 7$ & $21 \pm 7$ & $16 \pm 10$ & $33 \pm 10$ \\
\hline $152 \pm 24$ & $166 \pm 7$ & $178 \pm 26$ & $183 \pm 10$ & $196 \pm 10$ \\
\hline $325 \pm 35$ & $336 \pm 7$ & $352 \pm 17$ & $350 \pm 10$ & $365 \pm 10$ \\
\hline $469 \pm 23$ & $512 \pm 7$ & $523 \pm 31$ & $516 \pm 10$ & $535 \pm 10$ \\
\hline \multirow[t]{3}{*}{$625 \pm 40$} & $649 \pm 7$ & $693 \pm 21$ & $686 \pm 10$ & $695 \pm 10$ \\
\hline & & $875 \pm 24$ & $851 \pm 10$ & $861 \pm 10$ \\
\hline & & $1052 \pm 17$ & $1003 \pm 10$ & $1014 \pm 10$ \\
\hline
\end{tabular}

a) Quoted values in column 1 and 3 correspond to 28/16 of the energy measured by the position of the submaxima. 
Fig. 3. First derivative of the retarding potential curves of $\mathrm{O}^{+} / \mathrm{CO}$ recorded for 30, 40, 60 and $100 \mathrm{eV}$ electrons.

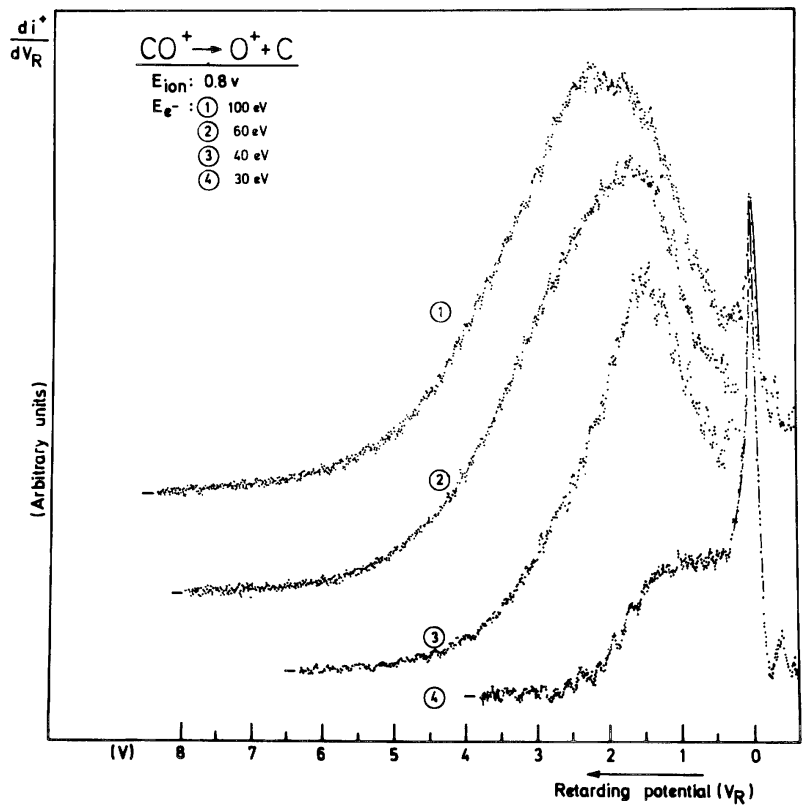

\subsection{Appearance potential measurements}

\subsubsection{Dissociation channel $\mathrm{CO} \stackrel{e_{-}^{-}}{\longrightarrow} \mathrm{C}^{+}+\mathrm{O}^{-}$and $\mathrm{C}^{+}+\mathrm{O}$}

A set of first derivatives of $\mathrm{C}^{+}$ionization efficiency curves recorded as a function of the retarding potential is shown in fig. 5. The critical energies, determined by the method described in section 2.2 are indicated by an arrow. Between 0.0 and $1.0 \mathrm{eV}$ retarding potential, ionization efficiency curves have been recorded at intervals of $0.1 \mathrm{~V}$; at higher energies these intervals are 0.2 and $0.5 \mathrm{~V}$. The result of these measurements is presented in a kinetic energy-versus-electron energy plot as shown in fig. 6.

Straight lines, drawn through the experimental points with a slope of $16 / 28$ result from the relation

$$
t\left(\mathrm{~A}^{+}\right)=m_{\mathrm{B}} T /\left(m_{\mathrm{A}}+m_{\mathrm{B}}\right),
$$

where $t\left(\mathrm{~A}^{+}\right)$and $T$ are the fragment ion energy and the total energy, respectively; $m_{\mathrm{A}}$ and $\mathrm{m}_{\mathrm{B}}$ are the masses of $\mathrm{A}^{+}$ and $\mathrm{B}$, respectively. For convenience in the discussion (section 4) the calculated position of the dissociation limits are listed in table 2 together with the corresponding dissociation products.

\subsubsection{Dissociation channel $\mathrm{CO} \stackrel{e^{-}}{\longrightarrow} \mathrm{O}^{+}+\mathrm{C}^{-}$and $0^{+}+\mathrm{C}$}

Fig. 7 shows first derivatives of ionization efficiency curves for $\mathrm{O}^{+}$ions produced by dissociative electroionization of $\mathrm{CO}$, as recorded for the indicated retarding potential values. This latter parameter has been increased by steps of $0.2 \mathrm{~V}$ between 0.0 and $2.0 \mathrm{~V}$. For the high ion energy range, an interval of $0.5 \mathrm{~V}$ has been chosen. The measured threshold energies of $\mathrm{O}^{+}$have been plotted in a kinetic energy-versus-electron energy diagram shown in fig. 8 . The experimental data fit fairly well the theoretical slope given by $m_{\mathrm{C}+} / m_{\mathrm{CO}}=12 / 28$.

For clarity in the following discussion the calculated position of the dissociation limits are listed in table 3 together with the corresponding dissociation products.

\subsubsection{The ionization efficiency curve of $\mathrm{CO}^{+}$}

In fig. 5 the first derivative of the $\mathrm{CO}^{+}$ionization efficiency curve has been reproduced as a reference for the electron energy scale calibration. Beneath the first steeply rising step corresponding to the first ionization energy of $\mathrm{CO}$, features are observed at higher electron energies. The critical energies, listed in table 4 do not 
correspond to known higher ionization limits of CO. Recently Carbonneau and Marmet [5] measured the electroionization efficiency curve of carbon monoxide and the fine structure detected between 15 and $18.5 \mathrm{eV}$ has been ascribed to auto-ionization. The position of the structures observed in the present work, though incompletely resolved (the fwhm of the electron energy distribution is $400 \mathrm{meV}$ instead of $80 \mathrm{meV}$ in ref. [5] ) corresponds fairly well to the first and most intense members of neutral autoionizing states of CO. This is summarized in table 4.

Fig. 4. First derivative of the retarding potential curves of $\mathrm{CO}^{+}(\mathrm{l})$ and $\mathrm{O}^{+}$(2) from $\mathrm{CO}$ recorded at $25 \mathrm{eV}$ electron energy.

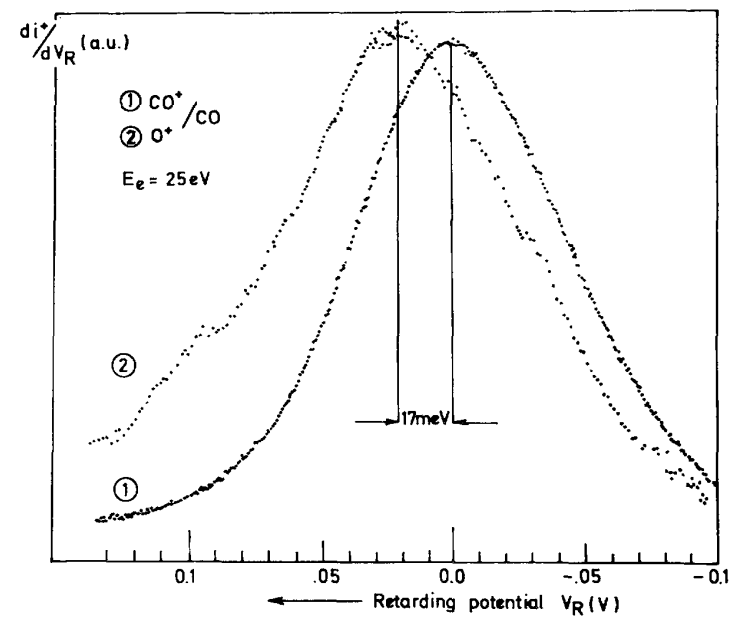

Fig. 5. First derivative of the $C^{+}$ionization efficiency curves recorded at indicated retarding potential $V_{R}$. The arrows show the position of the critical energies. The differentiated ionization efficiency curve of $\mathrm{CO}^{+}$is used for electron energy scale calibration.

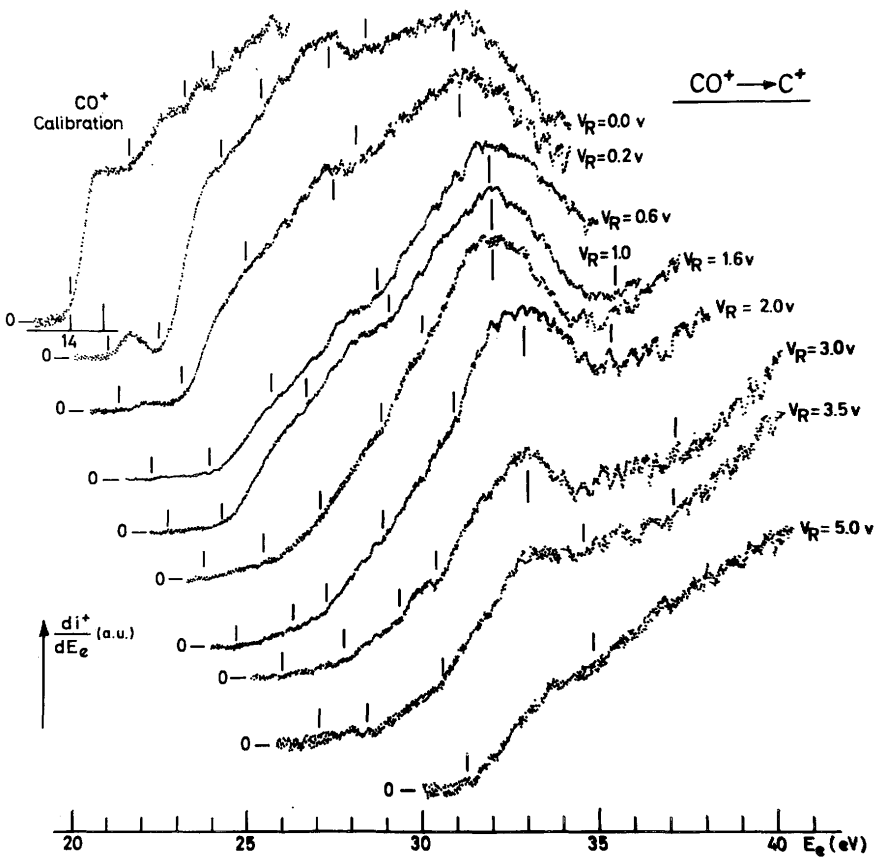


Fig. 6. Kinetic energy-versus-appearance energy plot for the dissociative ionization of $\mathrm{CO}$ leading to $\mathrm{C}^{+}+\mathrm{O}$ (or $\left.O^{-}\right)$. For the explanation of arrows 1-7 see text.

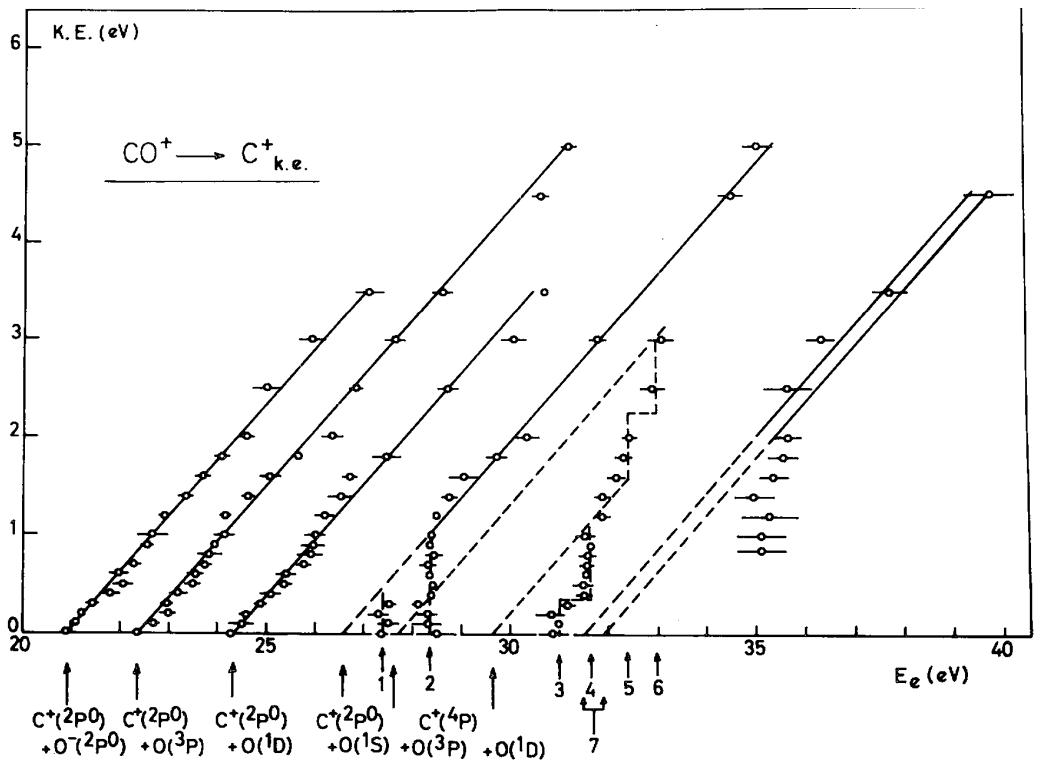

Table 2. Dissociation limits and products for $\mathrm{CO}^{+} \rightarrow \mathrm{C}^{+}+\mathrm{O}$ calculated using $\mathrm{D}_{0}{ }^{0}(\mathrm{CO})=11.109 \mathrm{eV}[20], \mathrm{IP}(\mathrm{CI})$ $=11.260 \mathrm{eV}$ [19] and $E A(O)=1.465 \mathrm{eV}$ [24]. The energy levels of $C^{+}$and $O$ are taken from ref. [25] $(1 \mathrm{eV}=$ $\left.8065.73 \mathrm{~cm}^{-1}\right)$

\begin{tabular}{ccc}
\hline Dissociation products & Energy (eV) \\
\hline $\mathrm{CO} \rightarrow \mathrm{C}^{+}\left({ }^{2} \mathrm{P}^{0}\right)+\mathrm{O}^{-}\left({ }^{2} \mathrm{P}\right)$ & $(1)$ & 20.904 \\
$\mathrm{CO}^{+} \rightarrow \mathrm{C}^{+}\left({ }^{2} \mathrm{P}^{0}\right)+\mathrm{O}\left({ }^{3} \mathrm{P}\right)$ & $(2)$ & 22.369 \\
$\mathrm{C}^{+}\left({ }^{2} \mathrm{P}^{0}\right)+\mathrm{O}\left({ }^{1} \mathrm{D}\right)$ & $(3)$ & 24.337 \\
$\mathrm{C}^{+}\left({ }^{2} \mathrm{P}^{0}\right)+\mathrm{O}\left({ }^{1} \mathrm{~S}\right)$ & $(4)$ & 26.560 \\
$\mathrm{C}^{+}\left({ }^{4} \mathrm{P}\right)+\mathrm{O}\left({ }^{3} \mathrm{P}\right)$ & $(5)$ & 27.700 \\
$\mathrm{C}^{+}\left({ }^{4} \mathrm{P}\right)+\mathrm{O}\left({ }^{1} \mathrm{D}\right)$ & $(6)$ & 29.668 \\
$\mathrm{C}^{+}\left({ }^{2} \mathrm{P}^{0}\right)+\mathrm{O}\left({ }^{5} \mathrm{~S}^{0}\right)$ & $(7)$ & 31.515 \\
$\mathrm{C}^{+}\left({ }^{2} \mathrm{D}\right)+\mathrm{O}\left({ }^{3} \mathrm{P}\right)$ & $(8)$ & 31.659 \\
$\mathrm{C}^{+}\left({ }^{2} \mathrm{P}^{0}\right)+\mathrm{O}\left({ }^{3} \mathrm{~S}^{0}\right)$ & $(9)$ & 31.890 \\
$\mathrm{C}^{+}\left({ }^{4} \mathrm{P}\right)+\mathrm{O}\left({ }^{1} \mathrm{~S}\right)$ & $(10)$ & 31.891 \\
$\mathrm{C}^{+}\left({ }^{2} \mathrm{P}^{0}\right)+\mathrm{O}\left({ }^{5} \mathrm{P}\right)$ & $(11)$ & 33.109 \\
\hline
\end{tabular}

\section{Discussion}

For the sake of clarity the two dissociation channels as well as the successively observed dissociation limits will be discussed separately in the following section.

Except those belonging to the $\mathrm{X}^{2} \Sigma^{+}, \mathrm{A}^{2} \Pi_{\mathrm{i}}$ and $\mathrm{B}^{2} \Sigma^{+}$states of $\mathrm{CO}^{+}$, the potential energy curves presented in this section are Morse potential curves. The parameters $D_{e}, \omega_{0}$ and $r_{\mathrm{e}}$ are tentatively evaluated from optical and from photo-electron spectroscopic data. The potential energy curves drawn with dashed lines are proposed on the basis of the following discussion. As a consequence their significance is strictly qualitative.

\subsection{Dissociation channel $\mathrm{CO} \stackrel{e_{-}^{-}}{\longrightarrow} \mathrm{C}^{+}+\mathrm{O}^{-}$at $(20.91 \pm 0.04) \mathrm{eV}$}

As shown in fig. 5 the first threshold measured at $(20.91 \pm 0.04) \mathrm{eV}$ belongs to the well defined peak in the first derivative of the $\mathrm{C}^{+}$ionization efficiency curve, corresponding to an ion pair formation through 


$$
\begin{aligned}
& \mathrm{CO}+\mathrm{e}^{-} \rightarrow \mathrm{CO}^{*}(\mathrm{Rydb} .)+\mathrm{e}^{-}, \\
& \mathrm{CO}^{*}(\mathrm{Rydb} .) \rightarrow \mathrm{C}^{+}\left({ }^{2} \mathrm{P}^{0}\right)+\mathrm{O}^{-}\left({ }^{2} \mathrm{P}\right) .
\end{aligned}
$$

This process has been studied in detail earlier [18]. The examination of the $\mathrm{C}^{+}$ion energy distribution near threshold (see fig. 3) allowed to describe process (1) in terms of a predissociation where the predissociated state $\mathrm{CO}^{*}$ should be the $3 \mathrm{~d} \sigma$ or $3 \mathrm{p} \sigma$ Rydberg state [5] (see table 1a). This is schematically represented in fig. 9.

The first straight line in fig. 6 starting at $20.91 \mathrm{eV}$ and rising up to $3.5 \mathrm{eV}$ kinetic energy carried away by $\mathrm{C}^{+}$suggests that beneath the thermal peak, ion pairs with increasing translational energy are formed. This is in agreement with our previous experiments on $\mathrm{O}^{-}$produced by electron impact on $\mathrm{CO}$ [18] and with the $\mathrm{O}^{-}$kinetic energy distribution obtained by Köllmann [12]. It is also evident from the ionization efficiency curve of () $)^{-}$that several $\mathrm{CO}^{*}$ states are involved in the ion pair formation over the range of $21-26 \mathrm{eV}$ electron energy [18].

\subsection{Dissociation channel $\mathrm{CO}^{+} \stackrel{e_{-}^{-}}{\longrightarrow} \mathrm{C}^{+}+\mathrm{O}$}

\subsubsection{Dissociation limit at $(22.35 \pm 0.05) \mathrm{eV}$}

As shown in fig. 6, a straight line with a slope of $m_{\mathrm{O}+} / m_{\mathrm{CO}}=16 / 28$ starts at $22.35 \mathrm{eV}$ and extends over 5 $\mathrm{eV}$. The threshold measured at $\mathrm{KE}=0 \mathrm{eV}$ is in good agreement with the calculated value of $22.369 \mathrm{eV}$ for the dissociation channel 2 listed in table 2. The ion energy range covered by this process is in good agreement with the experimental results of Kollmann [12] and Smyth et al. [14]. It has to be pointed out that the present experiment has been limited on the high energy side of the kinetic energy scale for signal intensity reasons. Because of this limitation, the first derivatives of the ionization efficiency curves at 4.0, 4.5 and 5.0 eV minimum kinetic energy had to be stored during $72 \mathrm{~h}$ in order to obtain a satisfactory signal-to-noise ratio.

As discussed earlier [15] the low energy portion of the straight line starting at $22.35 \mathrm{eV}$ can be interpreted by the predissociation of the $\mathrm{D}^{2} \Pi$ state of $\mathrm{CO}^{+}$. This interpretation is supported by the existence of a fine structure in the ion energy spectrum of $\mathrm{C}^{+}$recorded near threshold (fig. 2). The position of the peak maxima (see table lb) agrees fairly well with the vibrational spacings of the $\mathrm{D}^{2} \Pi$ state of $\mathrm{CO}^{+}$observed by photo-electron spectroscopy $[3,4]$. This situation is represented schematically in fig. 9 .

To interpret the medium and high ion energy portion of the straight line extrapolated to $22.35 \mathrm{eV}$, doublet and quartet $\Sigma^{+}, \Sigma^{-}[2], \Pi[2]$ and $\Delta$ states, arising from the ${ }^{2} \mathrm{P}^{0}-{ }^{3} \mathrm{P}$ combination, could be involved. The interpretation is uneasy owing to lack of spectroscopic data and theoretically predicted potential energy curves.

Fig. 7. First derivative of the $\mathrm{O}^{+}$ionization efficiency curves recorded at different retarding potential values. The arrows locate the critical energies.

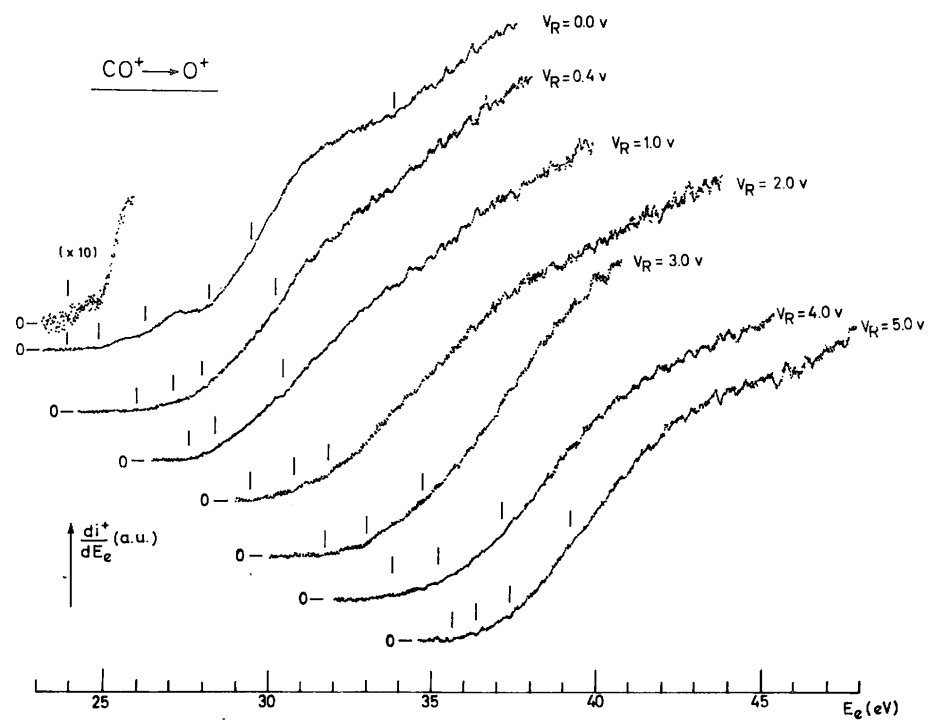


Fig. 8. Kinetic energy-versus-appearance energy plot for the dissociative ionization of CO leading to $\mathrm{O}^{+}+\mathrm{C}(\mathrm{or}$ C).

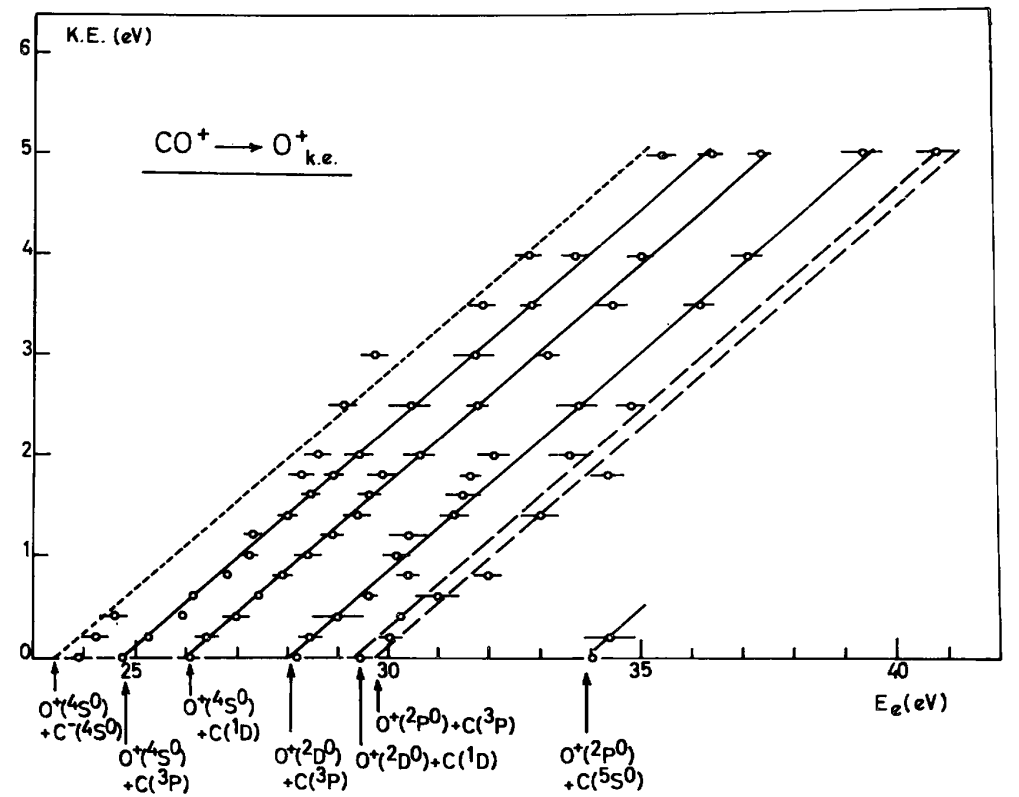

Table 3. Dissociation limits and products for $\mathrm{CO}^{+} \rightarrow C+\mathrm{O}^{+}$calculated using $\mathrm{D}_{0}{ }^{0}(\mathrm{CO})=11.109 \mathrm{eV}$ [20], IP(OI) $=13.618 \mathrm{eV}$ [19] and $E A(C)=1.268 \mathrm{eV}$ [24]. The energy levels of $C$ and $O^{+}$are taken from ref. [25] $(1 \mathrm{eV}=$ $\left.8065.73 \mathrm{~cm}^{-1}\right)$

\begin{tabular}{ccc}
\multicolumn{2}{c}{ Dissociation products } & Energy $(\mathrm{eV})$ \\
\hline $\mathrm{CO} \rightarrow \mathrm{C}\left({ }^{4} \mathrm{~S}\right)+\mathrm{O}^{+}\left({ }^{4} \mathrm{~S}^{0}\right)$ & $(1)$ & 23.459 \\
$\mathrm{CO} \rightarrow \mathrm{C}\left({ }^{3} \mathrm{P}\right)+\mathrm{O}^{+}\left({ }^{4} \mathrm{~S}^{0}\right)$ & $(2)$ & 24.727 \\
$\mathrm{C}\left({ }^{1} \mathrm{D}\right)+\mathrm{O}^{+}\left({ }^{4} \mathrm{~S}^{0}\right)$ & $(3)$ & 25.991 \\
$\mathrm{C}\left({ }^{1} \mathrm{~S}\right)+\mathrm{O}^{+}\left({ }^{4} \mathrm{~S}^{0}\right)$ & $(4)$ & 27.411 \\
$\mathrm{C}\left({ }^{3} \mathrm{P}\right)+\mathrm{O}^{+}\left({ }^{2} \mathrm{D}^{0}\right)$ & $(5)$ & 28.052 \\
$\mathrm{C}\left({ }^{5} \mathrm{~S}^{0}\right)+\mathrm{O}^{+}\left({ }^{4} \mathrm{~S}^{0}\right)$ & $(6)$ & 28.909 \\
$\mathrm{C}\left({ }^{1} \mathrm{D}\right)+\mathrm{O}^{+}\left({ }^{2} \mathrm{D}^{0}\right)$ & $(7)$ & 29.317 \\
$\mathrm{C}\left({ }^{3} \mathrm{P}\right)+\mathrm{O}^{+}\left({ }^{2} \mathrm{P}^{0}\right)$ & $(8)$ & 29.746 \\
$\mathrm{C}\left({ }^{1} \mathrm{~S}\right)+\mathrm{O}^{+}\left({ }^{2} \mathrm{D}^{0}\right)$ & $(9)$ & 30.736 \\
$\mathrm{C}\left({ }^{1} \mathrm{D}\right)+\mathrm{O}^{+}\left({ }^{2} \mathrm{P}^{0}\right)$ & $(10)$ & 31.011 \\
$\mathrm{C}\left({ }^{5} \mathrm{P}^{0}\right)+\mathrm{O}^{+}\left({ }^{4} \mathrm{~S}^{0}\right)$ & $(11)$ & 32.207 \\
$\mathrm{C}\left({ }^{5} \mathrm{~S}^{0}\right)+\mathrm{O}^{+}\left({ }^{2} \mathrm{D}^{0}\right)$ & $(12)$ & 32.234 \\
$\mathrm{C}\left({ }^{1} \mathrm{~S}\right)+\mathrm{O}^{+}\left({ }^{2} \mathrm{P}^{0}\right)$ & $(13)$ & 32.430 \\
$\mathrm{C}\left({ }^{5} \mathrm{~S}^{0}\right)+\mathrm{O}^{+}\left({ }^{2} \mathrm{P}^{0}\right)$ & $(14)$ & 33.928 \\
$\mathrm{C}\left({ }^{5} \mathrm{P}^{0}\right)+\mathrm{O}^{+}\left({ }^{2} \mathrm{D}^{0}\right)$ & $(15)$ & 35.532 \\
$\mathrm{C}\left({ }^{2} \mathrm{P}^{0}\right)+\mathrm{O}^{+}\left({ }^{4} \mathrm{~S}^{0}\right)$ & $(16)$ & 35.987 \\
$\mathrm{C}\left({ }^{5} \mathrm{P}^{0}\right)+\mathrm{O}^{+}\left({ }^{2} \mathrm{P}^{0}\right)$ & $(17)$ & 37.226 \\
$\mathrm{C}\left({ }^{3} \mathrm{P}\right)+\mathrm{O}^{+}\left({ }^{4} \mathrm{P}\right)$ & $(18)$ & 39.584 \\
\hline
\end{tabular}

However, $\Sigma^{-} \leftarrow \Sigma^{+}$transitions have to be excluded as being forbidden by Dunn's selection rules [13]. Furthermore, if not involved in the predissociation of the $\mathrm{D}^{2} \Pi$ state [15], the transition to the ${ }^{2} \Delta_{\mathrm{r}}$ state of $\mathrm{CO}^{+}$ could be considered at least in the medium ion energy range. This state is mainly repulsive in the FranckCondon region (see fig. 10). The angular distribution has to be anisotropic and has to show a maximum at an angle $\theta=90^{\circ}$ between electron and ion beams. Köllmann [12] showed recently that the angular distribution for $\mathrm{C}^{+}$at $40 \mathrm{eV}$ electron energy and 2.2, 3.2 and $4.2 \mathrm{eV}$ ion energy exhibits an isotropic component, ascribed to $\Sigma^{+}$ $\leftarrow \Sigma^{+}$transitions and an anisotropic component characterized by a minimum in the forward-backward 
Table 4. Structure observed in the first derivative of the $\mathrm{CO}^{+}$ionization efficiency curve. Critical energies are given in $\mathrm{eV}$. The quoted error is the standard deviation $\sigma$

\begin{tabular}{cccc}
\hline State & $\begin{array}{c}\text { Parent } \\
\text { state }\end{array}$ & \multicolumn{2}{c}{ Energy } \\
\cline { 3 - 4 } & & ref. [5] a) & this work \\
\hline $4 \mathrm{~d} \sigma, v=0$ & $\mathrm{~A}^{2} \Pi$ & 15.63 & $15.75 \pm 0.14$ \\
$4 \mathrm{~d} \sigma, v=1$ & & 15.80 & \\
$3 \mathrm{p} \pi, v=0$ & $\mathrm{~B}^{2} \Sigma^{+}$ & 17.28 & $17.41 \pm 0.08$ \\
$4 \mathrm{~s} \sigma, v=0$ & $\mathrm{~B}^{2} \Sigma^{+}$ & 18.20 & $18.24 \pm 0.09$
\end{tabular}

a) Mentioned error $= \pm 0.0125 \mathrm{eV}$.

Fig. 9. Morse potential energy curves of $\mathrm{CO}^{+}$in the energy range where the dissociative ionization processes $\mathrm{CO} \rightarrow \mathrm{C}^{+}\left({ }^{2} P^{0}\right)+O^{-}\left({ }^{2} P^{0}\right)$ and $\left.\mathrm{CO}^{+} \rightarrow C^{+}\left({ }^{2} P^{0}\right)+O{ }^{\beta} P\right)$ are observed. The arrows show the position of the maxima observed in the $C^{+}$energy distribution.

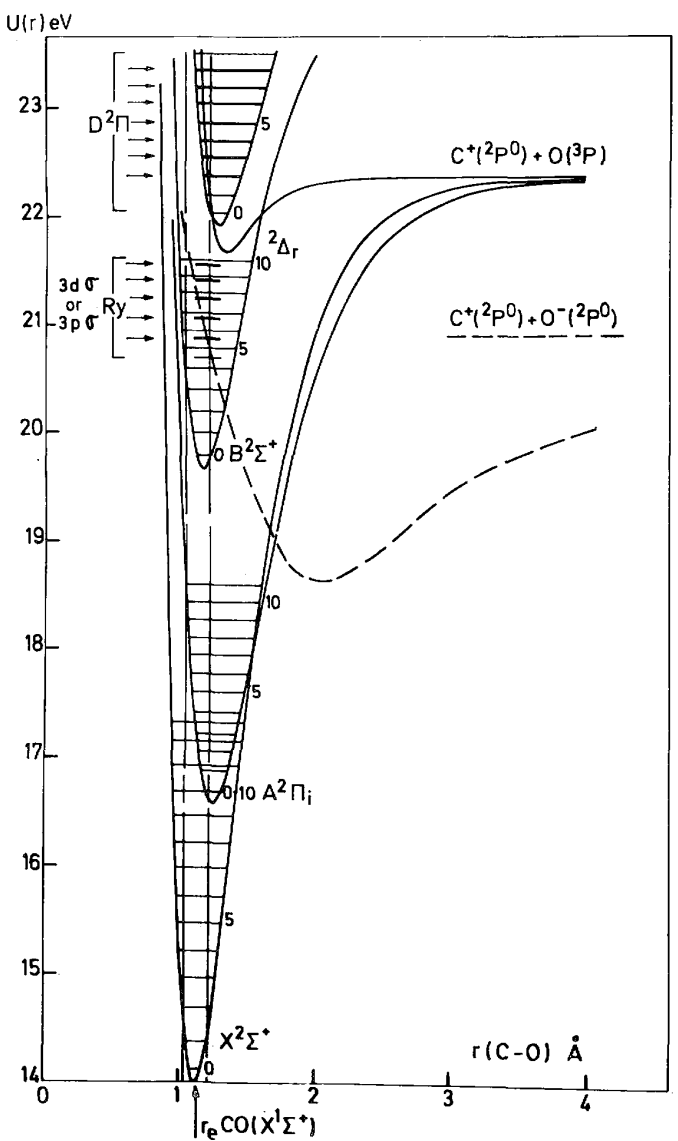

direction. This observation made $\Pi \leftarrow \Sigma^{+}$and $\Delta \leftarrow \Sigma^{+}$transitions unallowed [13]. At $40 \mathrm{eV}$ electron energy, a large number of transitions are involved (see table 2 and fig. 6) and thus the angular distributions observed have to be ascribed to the superposition of different types of transitions. As a result a contribution of a $\Delta \leftarrow \Sigma^{+}$ transition to these distributions cannot be ruled out.

Beneath the dissociative ionization via a possible transition to the ${ }^{2} \Delta$ state, medium and highly energetic $\mathrm{C}^{+}$ions can be produced by transitions to repulsive quartet states converging to the dissociation limit at 22.35 $\mathrm{eV}$.

\subsubsection{Dissociation limit at $(24.23 \pm 0.03) \mathrm{eV}$}

The third threshold observed at $(24.23 \pm 0.03) \mathrm{eV}$ in the first derivative of the $\mathrm{C}^{+}$ionization efficiency 
curve is in fairly good agreement with the calculated dissociation limit at $24.337 \mathrm{eV}$ for process 3 in table 2 . This process has been observed by Smyth et al. [14] by means of high-Rydberg C-atom detection and has not been observed by Köllmann [12].

In charge transfer experiments involving $\mathrm{CO}$ and $\mathrm{He}^{+}$, for which the recombination energy is $24.587 \mathrm{eV}$ [19], Derrick and Szabo [21] observed $\mathrm{C}^{+}$ions, mainly as primary ions. Using $\mathrm{He}^{+}$in a charge exchange reaction with $\mathrm{CO}$ the intensity of the metastable peak corresponding to $\mathrm{CO}^{+}$(metast.) $\rightarrow \mathrm{C}^{+}+\mathrm{O}$ in the first field free region of the double focussing mass spectrometer AEI-MS9 remains unchanged [11]. Furthermore at low ion energies no evidence is found for additional structure due to a predissociation to this limit. Consequently the dissociative ionization observed at $24.23 \mathrm{eV}$ is the result of a direct transition to the dissociative part of a stable $\mathrm{CO}^{+}$electronic state.

Concerning the symmetry of the molecular ion state(s) involved over the whole ion energy range $(0-3$ eV) no answer could be found in the angular distribution experiments. The photoelectron spectrum of $\mathrm{CO}$ [4] provides no evidence for the existence of direct dissociative ionization in the range of $24-30 \mathrm{eV}$ electron binding energy. In this energy range only the $\mathrm{E}^{2} \Sigma^{+}$and the $\mathrm{F}^{2} \Sigma^{+}$states of $\mathrm{CO}^{+}$have been observed.

\subsubsection{Dissociation limit at $26.6 \mathrm{eV}$}

No direct dissociative ionization is observed at this limit. The energy of $26.6 \mathrm{eV}$ obtained by linear extrapolation corresponds to process 4 in table 2

$$
\mathrm{CO}^{+} \rightarrow \mathrm{C}^{+}\left({ }^{2} \mathrm{P}^{0}\right)+\mathrm{O}\left({ }^{1} \mathrm{~S}\right)
$$

and $\mathrm{C}^{+}$ions are formed with a minimum kinetic energy of $(1.1 \pm 0.1) \mathrm{eV}$. The threshold for this process is $(28.36$ $\pm 0.08) \mathrm{eV}$ as averaged over the $0-1.2 \mathrm{eV}$ ion energy range (arrow $2 \mathrm{in}$ fig. 6). Above this energy the straight line extends up to $5 \mathrm{eV}$ kinetic energy. These results are in very good agreement with those obtained by Smyth et al. [14] by means of dissociative excitation of $\mathrm{CO}$ by electron impact.

The combination of ${ }^{2} \mathrm{P}^{0}$ and ${ }^{1} \mathrm{~S}$ terms gives rise to one ${ }^{2} \Sigma^{+}$and one ${ }^{2} \Pi$ state only. The relatively intense process observed at $28.36 \mathrm{eV}$ could be ascribed to a ${ }^{2} \Sigma^{+} \leftarrow \mathrm{X}^{1} \Sigma^{+}$transition and could at least partially account for the results obtained by Köllmann [12] at $40 \mathrm{eV}$ electron energy.

The ${ }^{2} \Sigma^{+}$state involved in this process should be characterized by a large equilibrium internuclear distance. This is the case when the ${ }^{2} \Sigma^{+}$state correlated with ${ }^{2} \mathrm{P}^{0}+{ }^{1} \mathrm{~S}$ and the $\mathrm{C}^{2} \Sigma^{+}$correlated with ${ }^{2} \mathrm{P}^{0}+{ }^{1} \mathrm{D}$, give rise to an avoided crossing. For the latter, the particularly large $x_{\mathrm{e}} \omega_{\mathrm{e}}$ value has to be ascribed to an anomalous potential curve [3]. This situation is schematically drawn in fig. 10.

The position of the first maximum observed in the first derivative of the $\mathrm{C}^{+}$ionization efficiency curve at low ion energies, i.e. in the range of $0.0-0.3 \mathrm{eV}$, has been investigated as a function of the retarding potential. The result is indicated by arrow 1 in fig. 6 . This process at $27.4 \mathrm{eV}$ corresponds to dissociative autoionization as observed previously in $\mathrm{N}^{+}$from $\mathrm{N}_{2}$ [17]. The most probable mechanism is

$$
\begin{aligned}
& \mathrm{CO}+\mathrm{e}^{-} \rightarrow \mathrm{CO}^{*}+\mathrm{e}^{-} \\
& \mathrm{CO}^{*} \rightarrow \mathrm{CO}^{+}\left({ }^{2} \Pi ?\right)+\mathrm{e}^{-} \\
& \stackrel{\mathrm{C}^{+}\left({ }^{2} \mathrm{P}^{0}\right)+\mathrm{O}\left({ }^{1} \mathrm{~S}\right),}{\longrightarrow}
\end{aligned}
$$

where the $\mathrm{CO}$ state involved could be the ${ }^{2} \Pi$ state correlated with the dissociation limit at $26.6 \mathrm{eV}$.

\subsubsection{Dissociations in the energy range of $31-33 \mathrm{eV}$}

The critical energy measurements plotted in this ion energy range correspond to the maximum of the second peak observed in the first derivative of the $\mathrm{C}^{+}$ionization efficiency curve (arrows $3-6$ in fig. 6). This peak has to be ascribed to autoionization and no direct dissociative ionization is observed. Furthermore the measured critical energies do not fit a straight line extrapolated to a $\mathrm{CO}^{+}$dissociation limit. The transition between arrow 3, corresponding to an energy of $(31.0 \pm 0.2) \mathrm{eV}$, and arrow 4 at an energy of $(31.5 \pm 0.1) \mathrm{eV}$, is stepwise. Although less clearly, the same stepwise feature is observed between $32.4 \mathrm{eV}$ (arrow 5) and $33.0 \mathrm{eV}$ (arrow 6). 
Fig. 10. Morse potential energy curves of $\mathrm{CO}^{+}$leading to the dissociation $\mathrm{C}^{+}+\mathrm{O}$ (full lines). Potential energy curves drawn by dashed lines are inferred from the present work. Shaded area noted by $\mathrm{CO}_{1}{ }^{*}-\mathrm{CO}_{6}{ }^{*}$, corresponding to arrows 1-6 in fig. 6 are the energy ranges where dissociative autoionization is observed.

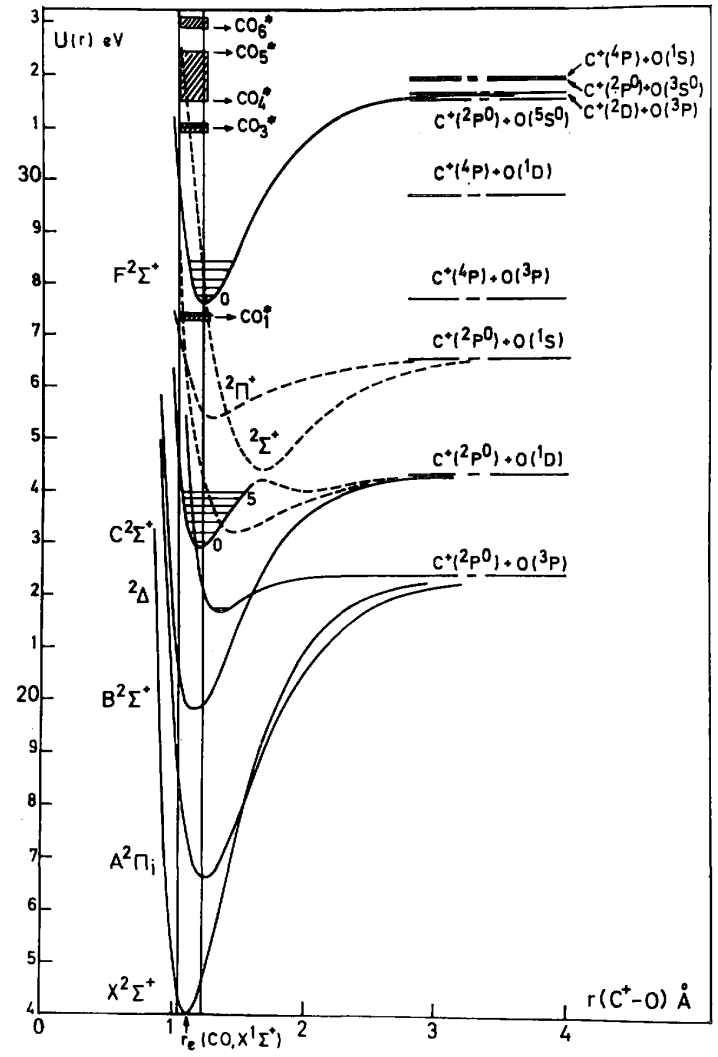

One of the most probable interpretations of this result is the dissociative autoionization, i.e.

$$
\begin{aligned}
& \mathrm{CO}+\mathrm{e}^{-} \rightarrow \mathrm{CO}^{*}+\mathrm{e}^{-}, \\
& \mathrm{CO}^{*} \rightarrow \mathrm{CO}^{+}+\mathrm{e}^{-} \\
& \stackrel{\longrightarrow}{\longrightarrow} \mathrm{C}^{+}\left({ }^{4} \mathrm{P}\right)+\mathrm{O}\left({ }^{1} \mathrm{D}\right) .
\end{aligned}
$$

If the autoionizing $\mathrm{CO}^{*}$ state is characterized by an equilibrium internuclear distance $r_{\mathrm{e}}$ nearly equal to that of the $\mathrm{CO}$ ground state, mainly the $v=0$ level of the former state is populated. This vibronic $\mathrm{CO}^{*}$ state can autoionize via a transition to the dissociation continuum of a molecular ion state lying slightly outside the Franck-Condon region. This mechanism could be invoked to explain the critical energies at 31.0 and $32.4 \mathrm{eV}$. It seems also reasonable to suggest that autoionization and subsequent dissociation lead to the nearest lower lying dissociation limit, i.e. $29.668 \mathrm{eV}$. However, at $33 \mathrm{eV}$ it seems (see fig. 6) that the dissociation should take place at the $27.8 \mathrm{eV}$ limit corresponding to $\mathrm{CO}^{+} \rightarrow \mathrm{C}^{+}\left({ }^{4} \mathrm{P}\right)+\mathrm{O}\left({ }^{3} \mathrm{P}\right)$.

In the energy range of 31.5 to $32.4 \mathrm{eV}$ the measured critical energies might fit a straight line having the expected 16/28 slope. This process may be ascribed to the population of an increasing number of vibrational levels of an autoionizing state giving rise to a broad ion energy distribution.

\subsubsection{Dissociation limits in the energy range of $31.5-31.9 \mathrm{eV}$}

The first threshold concerning the dissociative ionization at these limits is meausred for $0.9 \mathrm{eV}$ kinetic energy. Below this energy the new dissociative ionization channel is obscured by the lower lying and intense dissociative autoionization phenomena. Furthermore, as seen from fig. 6, a large error is made in the critical energy measurement due to the slow increase of the first derivative and the associated high noise level. 
Because of the scattering of the data and the exis-tense of four closely lying dissociation limits in this energy range, it is not possible to ascribe unambiguously this dissociation process to one of the mechanisms 7 to 10 mentioned in table 2 .

\subsection{Dissociation channel $\mathrm{CO} \stackrel{e_{-}^{-}}{\longrightarrow} \mathrm{C}^{+}+0^{+}$at (23.9 \pm 0.2$) \mathrm{eV}$}

In the conditions of high signal-to-noise ratio for the first derivative of the ionization efficiency curve of $\mathrm{O}^{+}$from $\mathrm{CO}$, a very weak signal could be detected below the first well defined threshold (see fig. 7). Its intensity, being at least one order of magnitude lower than the signal corresponding to the ion pair formation $\mathrm{CO} \rightarrow \mathrm{C}^{+}+$ $\mathrm{O}-$, enables a threshold energy to be measured only in a few favourable cases.

This signal rising up at $(23.9 \pm 0.2) \mathrm{eV}$ can only be ascribed to process 1 mentioned in table 3 and for which the threshold is calculated at $23.459 \mathrm{eV}$. Hierl and Franklin [8] measured an appearance energy at (23.2 \pm $0.05) \mathrm{eV}$. When the threshold energy is measured as a function of the retarding potential, the experimental points fit fairly well a straight line with the expected slope of $12 / 28$ drawn by a dashed line in fig. 8 . This observation also supports the interpretation that the weak signal observed around $23.9 \mathrm{eV}$ for $\mathrm{O}^{+}$is necessarily produced by dissociative ionization of $\mathrm{CO}$ only.

\subsection{Dissociation channel $\mathrm{CO}^{+} \stackrel{e_{-}^{-}}{\longrightarrow} \mathrm{C}+0^{+}$}

\subsubsection{Dissociation limit at $(24.75 \pm 0.09) \mathrm{eV}$}

The first steeply rising process detected in the first derivative of the ionization efficiency curve, recorded at $V_{\mathrm{R}}=0.0 \mathrm{~V}$, has its threshold at $(24.75 \pm 0.09) \mathrm{eV}$. This energy is in good agreement with that calculated for process 2 in table 3 and with previous measurements [8,12]. This process has not been observed by Smyth et al. [14] by means of translational spectroscopy of long lived high-Rydberg oxygen atoms. A straight line of slope $12 / 28$ starting at $24.75 \mathrm{eV}$ extends over the whole ion energy range investigated.

In the kinetic energy distribution of $\mathrm{O}^{+}$, the maximum of the nearly thermal peak is measured at $(17 \pm 4)$ $\mathrm{meV}$ for $25 \mathrm{eV}$ electrons, corresponding to $(39 \pm 9) \mathrm{meV}$ in terms of total kinetic energy (see fig. 4). At higher energies a broad and structurless peak is observed the shape and position of which drastically change between $35-30 \mathrm{eV}$.

Wankenne and Momigny [11] detected a very weak "metastable transition" at $m / e=9.14$ corresponding to the spontaneous decomposition $\mathrm{CO}^{+} \rightarrow \mathrm{O}^{+}+\mathrm{C}$ in the first field free region of a double focussing mass spectrometer. In this transition a small amount of kinetic energy is involved and a threshold energy has been measured at $(25 \pm 1) \mathrm{eV}$. When $\mathrm{He}$ is used in a charge exchange reaction with $\mathrm{CO}$, a significant increase in intensity is observed for both the metastable transition and the normal $\mathrm{O}^{+}$peak. These results are interpreted [11] by the formation of $\mathrm{O}^{+}$through the predissociation of a $\mathrm{CO}^{+}$vibronic state.

The peak observed at $39 \mathrm{meV}$ and the observation of a predissociation have to be interpreted by the process

$$
\mathrm{CO}^{+} \rightarrow \mathrm{O}^{+}\left({ }^{4} \mathrm{~S}^{0}\right)+\mathrm{C}\left({ }^{3} \mathrm{P}\right)
$$

combining ${ }^{3} \mathrm{P}$ and ${ }^{4} \mathrm{~S}^{0}$ terms, doublet, quartet and sextet $\Sigma^{+}$and $\Pi$ states are obtained. By estimation of its dissociation energy, the $\mathrm{D}^{2} \Pi$ state could converge to the $24.727 \mathrm{eV}$ limit at large internuclear distances. Dissociation of $\mathrm{CO}^{+}$by a direct transition to the continuum of this state is unlikely. In the energy range of interest the $\mathrm{E}^{2} \Sigma^{+}$state of $\mathrm{CO}^{+}$is also known by photoelectron spectroscopy [4]. Since allowed by Dunn's selection rules [13], this electronic state could be involved in a $\mathrm{E}^{2} \Sigma^{+} \leftarrow \mathrm{X}^{1} \Sigma^{+}$transition and predissociated via a repulsive $\mathrm{CO}^{+}$electronic state converging to $24.727 \mathrm{eV}$. The first observed vibrational level of the $\mathrm{E}^{2} \Sigma^{+}$state has been measured at $24.770 \mathrm{eV}$ [4]. If this level is predissociated, the total excess energy involved in process 2 in table 3 is $43 \mathrm{meV}$ which has to be compared with the total kinetic energy of (39 \pm 9$) \mathrm{meV}$ measured for the first peak observed in the kinetic energy distribution of $\mathrm{O}^{+}$.

In $\mathrm{N}_{2}{ }^{+}$, isoelectronic with $\mathrm{CO}^{+}$, the frequently studied process [17]

$$
\mathrm{N}_{2}^{+}\left(\mathrm{C}^{2} \Sigma_{\mathrm{u}}^{+}\right) \rightarrow \mathrm{N}^{+}\left({ }^{3} \mathrm{P}\right)+\mathrm{N}\left({ }^{4} \mathrm{~S}^{0}\right)
$$


has been described in terms of the predissociation of the $\mathrm{C}^{2} \Sigma_{\mathrm{u}}{ }^{+}$state via accidental predissociation involving a ${ }^{4} \Pi_{\mathrm{u}}$ bound state of $\mathrm{N}_{2}^{+}$[22] or a homogeneous predissociation due to $\mathrm{B}^{2} \Sigma^{+}-\mathrm{C}^{2} \Sigma_{\mathrm{u}}^{+}$interaction [23]. For the dissociative ionization channel of $\mathrm{CO}^{+}$at $24.72 \mathrm{eV}$

$$
\mathrm{CO}^{+}\left(\mathrm{E}^{2} \Sigma^{+}\right) \rightarrow \mathrm{C}\left({ }^{3} \mathrm{P}\right)+\mathrm{O}^{+}\left({ }^{4} \mathrm{~S}^{0}\right)
$$

both mechanisms could account for the experimental data. At least a predissociation ${ }^{4} \Pi-\mathrm{E}^{2} \Sigma^{+}$could be invoked (see fig. 11).

About the production of more energetic $0^{+}$ions, i.e. in the range of $1.0-3.0 \mathrm{eV}$, by dissociative ionization at $24.727 \mathrm{eV}$, valuable information is obtained from the kinetic energy distribution recorded with 30 $\mathrm{eV}$ electrons as well as from the angular distribution for $3 \mathrm{eV}$ ions at $32 \mathrm{eV}$ electron energy [12].

The kinetic energy distribution shows one energetic process peaking at $0.8 \mathrm{eV}$ and extending up to about $2.7 \mathrm{eV}$. The same peak shifts to $1.4 \mathrm{eV}$ at $35 \mathrm{eV}$ electron energy. The angular distribution of $0^{+}$[12] clearly shows minima at $\theta=60^{\circ}$ and $120^{\circ}$ and as a result $\Sigma^{+}, \Pi \leftarrow \Sigma^{+}$transitions have to be considered. Comparing $\mathrm{CO}^{+}$ with the isoelectronic $\mathrm{N}_{2}^{+}$molecule, the final state which gives rise to $\mathrm{O}^{+}$carrying a large amount of kinetic energy could be the ${ }^{4} \Sigma^{+}$electronic state of $\mathrm{CO}^{+}$(see fig. 11).

Fig. 11. Morse potential curves of $\mathrm{CO}^{+}$dissociating into $\mathrm{O}^{+}+C$ in the energy range close to the first threshold of the $\mathrm{O}^{+}$ion.

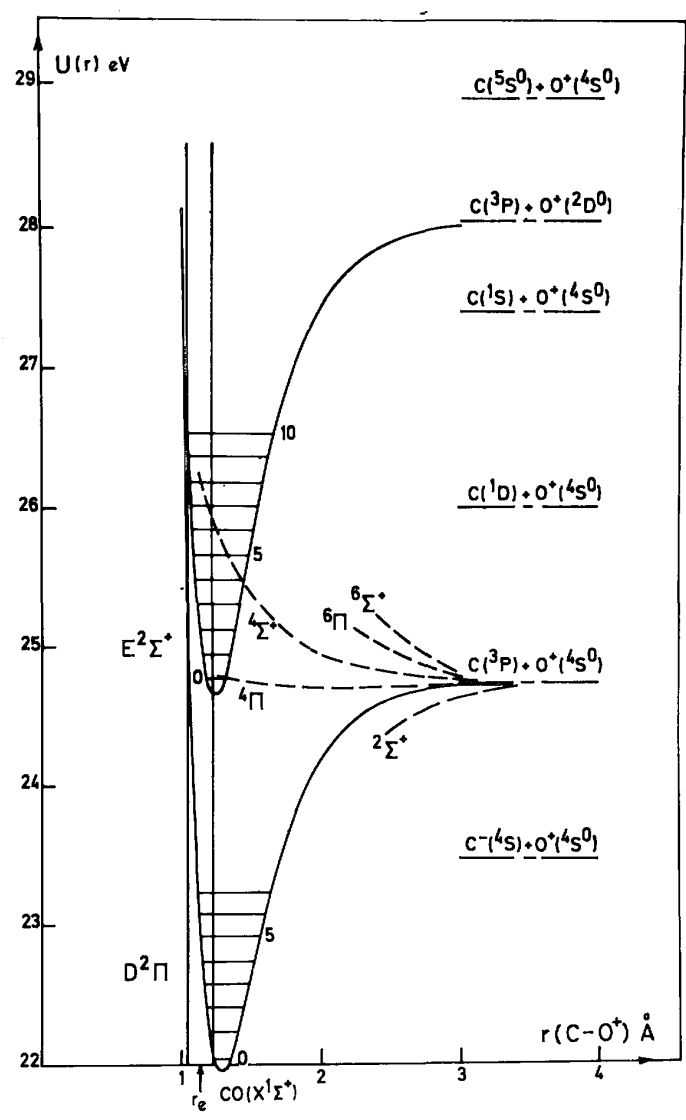

\subsubsection{Dissociation limit at $(26.07 \pm 0.19) \mathrm{eV}$}

The second well defined step is characterized by a threshold energy of $(26.07 \pm 0.19) \mathrm{eV}$, starting point of a straight line of slope 12/28 extending from 0 to $5 \mathrm{eV}$ kinetic energy. This measurement is in good agreement with the appearance energy measured for process 3 in table 3

$$
\mathrm{CO}^{+} \rightarrow \mathrm{C}\left({ }^{1} \mathrm{D}\right)+\mathrm{O}^{+}\left({ }^{4} \mathrm{~S}^{0}\right)
$$


calculated at $25.991 \mathrm{eV}$. This process has previously been observed by Hierl and Franklin [8] and Köllmann [12]. Again Smyth et al. [14] do not observe this process through high-Rydberg atom translational spectroscopy.

Although in this energy range the scarcity of the data does not allow us to discuss the process in detail, some information can be obtained about the symmetry of the states involved.

${ }^{4} \mathrm{~S}^{0}$ and ${ }^{1} \mathrm{D}$ terms could only give rise to quartet $\Sigma^{-}, \Pi$ and $\Delta$ states of $\mathrm{CO}^{+}$. Taking into account (i) Dunn's selection rules according to which $\Sigma^{-} \leftarrow \Sigma^{+}$transitions are forbidden and (ii) the angular distribution of $\mathrm{O}^{+}$ which shows a dominant contribution of $\Sigma^{+}, \Pi \leftarrow \Sigma^{+}$transitions, only a $\Pi \leftarrow \Sigma^{+}$transition is allowed. However, $\Delta \leftarrow \Sigma^{+}$transitions cannot be ruled out and both $\Pi, \Delta \leftarrow \Sigma^{+}$transitions have to be considered in the whole ion energy range.

\subsubsection{Dissociation limit at (28.21 \pm 0.13$) \mathrm{eV}$}

The unambiguous interpretation of the well resolved threshold energy at $(28.21 \pm 0.13) \mathrm{eV}$ is process 5 in table 3 for which an energy of $28.052 \mathrm{eV}$ is calculated. This process has been observed earlier by Hierl and Franklin [8] and Köllmann [12]. The first dissociative excitation process giving rise to oxygen high-Rydberg atoms [14] would have an energy of $27.4 \mathrm{eV}$ by extrapolation to $0 \mathrm{eV}$ released kinetic energy. In the R.P.D. ionization efficiency curve of $\mathrm{O}^{+}[8]$ a "break" is located at $27.4 \mathrm{eV}$. This could not be confirmed in the present experiment. From an examination of fig. 7 the absence of any dissociative ionization process at $27.4 \mathrm{eV}$ can unambiguously be inferred.

The number of possible molecular ion states involved in this (these) dissociative ionization process(es) leading to the limit at $28.2 \mathrm{eV}$ together with the total lack of data about $\mathrm{CO}^{+}$electronic states in this energy range, do not allow a more detailed discussion of the present data.

\subsubsection{Dissociation limits ranging $29.3-29.7 \mathrm{eV}$ and at $(34.06 \pm 0.12) \mathrm{eV}$}

The electron energy spread present in this experiment is not sufficient to resolve two processes $0.4 \mathrm{eV}$ apart. At $0 \mathrm{eV}$ kinetic energy a threshold is measured at $(29.45 \pm 0.24) \mathrm{eV}$. For higher values of the kinetic energy the diagram ion energy-versus-appearance energy follows roughly a straight line of slope $12 / 28$. It is not possible, however, to decide whether one or both processes 7 and 8 in table 3 are involved or not. Hierl and Franklin [8] and Köllmann [12] do not observed any "break" in the ionization efficiency curve of $\mathrm{O}^{+}$in the energy range of 29-30 eV. Smyth et al. [14] do not mention dissociative excitation processes in this energy range, the second process being mentioned by these authors is at about $32.5 \mathrm{eV}$ at $0 \mathrm{eV}$ released kinetic energy.

As shown in fig. 7, below $40 \mathrm{eV}$ electron energy, the first derivative of the $\mathrm{O}^{+}$ionization efficiency curve exhibits a slow rise at $(34.06 \pm 0.12) \mathrm{eV}$. The threshold energy of this process, being fairly easy to measure for zero $\mathrm{eV}$ retarding potential, could not be measured for higher retarding potentials due to a rapid lowering of the slope. As shown in fig. 8 , at $0.2 \mathrm{eV}$ retarding potential the scattering of 5 measurements is $0.5 \mathrm{eV}$.

Only process 14 in table 3 , for which a threshold of $33.928 \mathrm{eV}$ is calculated, could reasonably be invoked to interpret the process whose threshold is measured at $34.06 \mathrm{eV}$.

A more detailed interpretation of the high energetic process giving rise to $\mathrm{O}^{+}$is not possible without further information both from theory as well as from experiment.

\section{Conclusions}

In the present work on dissociative ionization in $\mathrm{CO}$ by electron impact the two exit channels, leading to either $\mathrm{C}^{+}$or $\mathrm{O}^{+}$for dissociation of the $\mathrm{CO}^{+}$molecular ion, have been studied in detail.

After the dissociative ionization study of $\mathrm{N}_{2}$ [16] and $\mathrm{O}_{2}$ [17], the following concluding remarks have to be extended to the dissociative ionization of CO. Even if the main limitation in the discussion of the experimental results is due to the total absence of theoretical work devoted to the CO molecule, this investigation clearly shows the major importance of two phenomena, i.e. predissociation and autoionization. While the former is necessarily present to produce both $\mathrm{C}^{+}+\mathrm{O}$ and $\mathrm{C}+\mathrm{O}^{+}$, all species being in their ground level, the latter seems to dominate at least for higher energies in the dissociation channel $\mathrm{CO}^{+} \rightarrow \mathrm{C}^{+}+\mathrm{O}$.

As already for $\mathrm{N}_{2}$ [16] and $\mathrm{O}_{2}$ [17], the present work again shows the advantage of combining both 
Published in: Chemical Physics (1977), vol. 22, pp. 13-27.

Status : Postprint (Author's Version)

kinetic energy analysis and the use of the first derivative of the electroionization efficiency curves to evidence the above-mentioned phenomena.

Finally it is noteworthy to point out that, although the data from dissociative excitation producing $\mathrm{C}$ high-Rydberg atoms agree with those from dissociative ionization forming $\mathrm{C}$ ions, both methods give different results for the second dissociation channel. No explanation has been found for this discrepancy.

\section{Acknowledgement}

The author gratefully thanks Professor J. Momigny and Dr. P. Natalis for stimulating discussions and useful suggestions. The Fonds de la Recherche Fondamentale Collective is acknowledged for financial support.

\section{References}

[1] P.H. Krupenie, The Band Spectrum of Carbon Monoxide, NSRDS-NBS-5 (1966).

[2] J. Marchand, J. D'Incan and J. Janin, Spectrochim. Acta 25A (1969) 605.

[3] K. Codling and A.W. Potts, J. Phys. B 7 (1974) 163.

[4] L. Åsbrink, C. Fridh, E. Lindholm and K. Codling, Phys-ica Scripta 10 (1974) 183.

[5] R. Carbonneau and P. Marmet, Can. J. Phys. 51 (1973) 2202.

[6] H. Lefebvre-Brion and CM. Moser, J. Mol. Spectry. 13 (1964) 418.

[7] F. Guerin, Theoret. Chim. Acta 17 (1970) 97.

[8] P.M. Hierl and J.L. Franklin, J. Chem. Phys. 47 (1967) 3154.

[9] H.D. Hagstrum, Rev. Mod. Phys. 23 (1951) 185.

[10] H.E. Stanton and J.E. Monahan, J. Chem. Phys. 41 (1974) 3694.

[11] H. Wankenne and J. Momigny, Chem. Phys. Letters 4 (1969) 132.

[12] K. Köllmann, Intern. J. Mass Spectrom. Ion Phys. 17 (1975) 261 ; J. Chem. Phys. 63 (1975) 1314; private communication.

[13] G.H. Dunn, Phys. Rev. Letters 8 (1962) 62.

[14] K.C. Smyth, J.A. Schiavone and R.S. Freund, J. Chem. Phys. 60 (1974) 1358.

[15] R. Locht and J.M. Durrer, Chem. Phys. Letters 34 (1975) 508.

[16] R. Locht and J. Schopman, Intern. J. Mass Spectrom. Ion Phys. 15 (1974) 361.

[17] R. Locht, J. Schopman, H. Wankenne and J. Momigny, Chem. Phys. 7 (1975) 393, and references therein.

[18] R. Locht and J. Momigny, Intern. J. Mass Spectrom. Ion Phys. 7(1971) 121.

[19] C.E. Moore, Ionization Potentials and Ionization Limits Derived from the Analysis of Optical Spectra, NSRDS-NBS 34 (1970).

[20] B. de B. Darwent, Bond Dissociation Energies in Simple Molecules, NSRDS-NBS 31 (1970).

[21] P.J. Derrick and I. Szabo, Intern. J. Mass Spectrom. Ion Phys. 7(1971) 71.

[22] A.J. Lorquet and J.C. Lorquet, Chem. Phys. Letters 26 (1974) 138. 
Published in: Chemical Physics (1977), vol. 22, pp. 13-27.

Status : Postprint (Author's Version)

[23] J. Tellinghuisen and D.L. Albritton, Chem. Phys. Letters 31 (1975) 91.

[24] H. Hotop and W.C. Lineberger, J. Phys. Chem. Ref. Data 4 (1975) 539.

[25] C.E. Moore, Atomic Energy Levels, vol. 1, NBS Circ. 467 (1949). 